\title{
Industrial based Smart Emergency Response System for Fire Disaster using loT
}

\author{
Vishal B. Rawat \\ BE, C.S.E \\ Bvcoe \& RI, Nashik \\ University of Pune
}

\author{
Mangesh A. Singh \\ BE, C.S.E \\ Bvcoe \& RI, Nashik \\ University of Pune
}

\author{
Swati A. Suryawanshi \\ BE, C.S.E \\ Bvcoe \& RI, Nashik \\ University of Pune
}

\author{
Priti S. Chabukswar \\ BE, C.S.E \\ Bvcoe \& RI, Nashik \\ University of Pune
}

\author{
Hemant D. Sonawane \\ H.O.D, C.S.E \\ Bvcoe \& RI, Nashik \\ University of Pune
}

\begin{abstract}
Industries around the world have become complex and augmented. Given the structural characteristics of modern industrial buildings, quick evacuation using emergency exits or evacuee guidance markers during blackouts due to fire, building collapse, earthquakes, or aging of industrial buildings need to be possible. An Industrial fire is a type of industrial disaster involving a conflagration which occurs in an industrial setting. Industrial fires often, but not always, occur together with explosions. They are most likely to occur in facilities where there is a lot of flammable material present. This paper suggests an Internet of Things (IoT)-based intelligent fire detection and emergency response system that can control directional guidance intelligently according to the time and location of a disaster using fuzzy logic and the design of an integrated control system using sensor networks to address the problems with existing fire emergency response systems in times of fire disaster.
\end{abstract}

\section{General Terms}

Algorithm-Fuzzy Logic Algorithm

\section{Keywords}

Internet of Things, Wireless sensor networks, Evacuation, Fire detection, Integrated Control System, fuzzy Logic

\section{INTRODUCTION}

Industrial-based intelligent smart emergency response system that can control security and safety of the industry intelligently within the minimum time and the design of a system using wireless sensor networks, fire alarm sensor, and human detecting sensor to address the problems with existing disaster emergency response systems in times of fire hazard. The system has decentralized control that can intelligently guide evacuees based on the detection of humans for removing them from industry to minimize the loss of human life and industrial assist. The existing system was able to secure the industry but not within enough time as the system was designed using various sensors but not as a single unit to address the problems in times of fire or any other. Each sensor were connected to the system separately and function individually which makes the system slow. The modified system can secure the industry intelligently within minimum time as the system is designed using different sensors as a single unit to address the problems in times of fire or any other.

\section{LITERATURE SURVEY}

In this section latest fire accident detection technologies and intelligent prevention system are discussed. In [1] an efficient smart emergency response system for fire hazards using IoT is explained in detail which provide a quality public safety and security services to adopt leveraged data driven emergency response systems with urban IoT design standards. In [2] an intelligent fire detection and mitigation system safe from fire (sff) is being specified in detail with proper safety system. In [3] the design and Implementation of a fire detection and control system for automobiles using fuzzy logic is given with early detection and exact fire location detection using fuzzy logic. In [4] the efficiency increase for electrical fire detection and alarm systems through implementation of fuzzy expert systems is explained with high efficiency detection system. In [5] the fire detection system using fuzzy logic and data aggregation using fuzzy logic is elaborated in detail. In [6] the Fire Detection System with GSM Using Arduino is explained which gives the approximation location of the fire. In [7] Internet of Things in Industries: A Survey is given which tells about the latest IOT based technologies used by industries in today's date. In [8] IoT-based Intelligent for Fire Emergency Response Systems explains the system designed using IOT for fire emergency response system. In [9] a study on the fire IOT development strategy gives the analysis on the development 
and advantages of fire IOT in several aspects, such as logistics of fighting products, the supervision of fighting product quality, the monitoring of construction firefighting facilities, the maintenance of firefighting facilities, home firefighting safety, firefighting equipment's etc. In [10] fire detection mechanism using fuzzy logic gives the improve accuracy of the detection system, as well as reduce the false alarm rate.

\section{SYSTEM OVERVIEW}

Internet of Things (IoT) has provided a promising opportunity to build powerful industrial systems and applications by leveraging the growing ubiquity of wireless sensor networks with radio-frequency identification (RFID), mobile and sensor devices. The entire proposed system is divided into two assembly points: Assembly point 1 and Assembly point 2.These assembly points are used both for security and safety purposes.

\subsection{Assembly Point 1}

Arduino based security system using RFID - The system designed under assembly point 1 as shown in figure 1 , is a security based system for industries. The system is fully automatic and does not require any manual operation. The system contains the following components:

\subsubsection{Arduino UNO R3 Board}

It is the main processing unit of the system which controls the output devices, reads input from the RFID reader and send messages to the LCD display.

\subsubsection{RFID Reader}

RFID reader detects the RFID card and send a 12 digits alphanumeric unique code on the serial port.

\subsubsection{Buzzer}

Buzzer is a warning or an indication that an invalid attempt is made to gain access to the system.

\subsubsection{NodeMCU ESP8266 Wifi Module}

Wifi module is a self-contained SOC with integrated TCP/IP protocol stack that can give any microcontroller access to your wifi network.

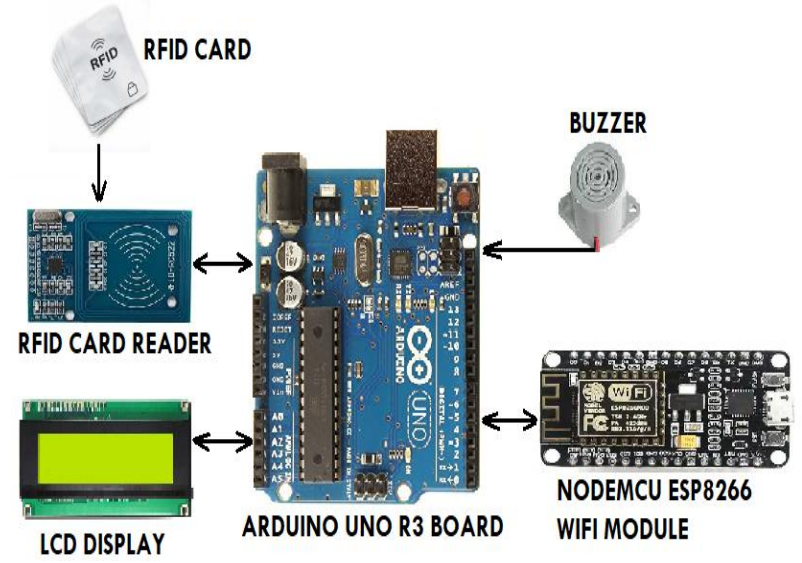

Fig 1: System Architecture of Assembly point 1-Arduino based security system using RFID

\subsection{Assembly Point 2}

Fire Detection and Water Sprinkler system - This proposed system detects fire at early stage as shown in figure 2 . This, in turn, helps in early reaction, solving lives and property of industries. It is totally designed for safety purposes. The proposed system can secure the industry intelligently within minimum time as the system is designed using different sensors as a single unit to address the problems in times of fire. Whenever the fire is detected by the sensor, it is indicated to the Arduino system. Then the Arduino takes the control action by switching on or off the water sprinkler with the help of relay coil and send a message or email to the industry incharge and to fire brigade to provide their safety service as early as possible. It allows for a quick assessment of the fire with decentralized control that can intelligently guide evacuees based on the detection of humans. It reduces casualties and the time required for evacuation by guiding evacuees that bypass the fire. The system contains the following components:

\subsubsection{Arduino UNO R3 Board}

Arduino board is the main processing board or unit of the system which controls the entire system.

\subsubsection{Buzzer/Alarm}

It is warning or alert indication buzzer.

\subsubsection{Power Supply}

Transformers/Battery adapter/9V high watt battery.

\subsubsection{SPDT Relay Coil}

Single pull double through relay for the purpose of AC appliances (ON and OFF).

\subsubsection{Water Sprinkler}

Water Sprinkler system is used for the purpose of reducing the fire and making the disaster under control.

\subsubsection{NodeMCU ESP8266 Wifi Module}

This wifi module can give any microcontroller access to your wifi network.

\subsubsection{Sensors}

\subsubsection{Thermistor Sensors (LM35)}

Thermistor Sensor Module is used to sense temperature and convert it into output signals.

\subsubsection{IR Sensors}

IR sensor can measure the heat of an object as well as detects the motion. These types of sensors measures only infrared radiation, rather than emitting it that is called as a passive IR sensor.

\subsubsection{Smoke/Gas Sensors (MQ5)}

Gas Sensor module is useful for gas leakage detection.

\subsubsection{PIR Sensors}

PIR sensors allow you to sense motion, almost always used to detect whether a human has moved in or out of the sensors range.

\subsubsection{GSM Module}

GSM module is used to establish communication between a mobile and a GSM system.

\subsection{System Flow}

Figure 3 shows the system working using system flow diagram. Whenever the fire disaster took place, the fire is initially detected by the flame IR sensor which collects and check the data. If the data is collected, then the gas and temperature sensors gets initialized which collects and measures the data. Further if the system finalize that the fire is actually occurred, the buzzer/alarm starts ringing after which the PIR sensor (Human detecting sensor) also gets initialized which counts the number of employees or persons passes 
through the exit point so that the system can identify the employees under danger and find those employees with the help of GPRS module. At last, the system automatically starts the water sprinkler and send a message or email to the industry in-charge and to fire-brigade to provide their safety service as early as possible.

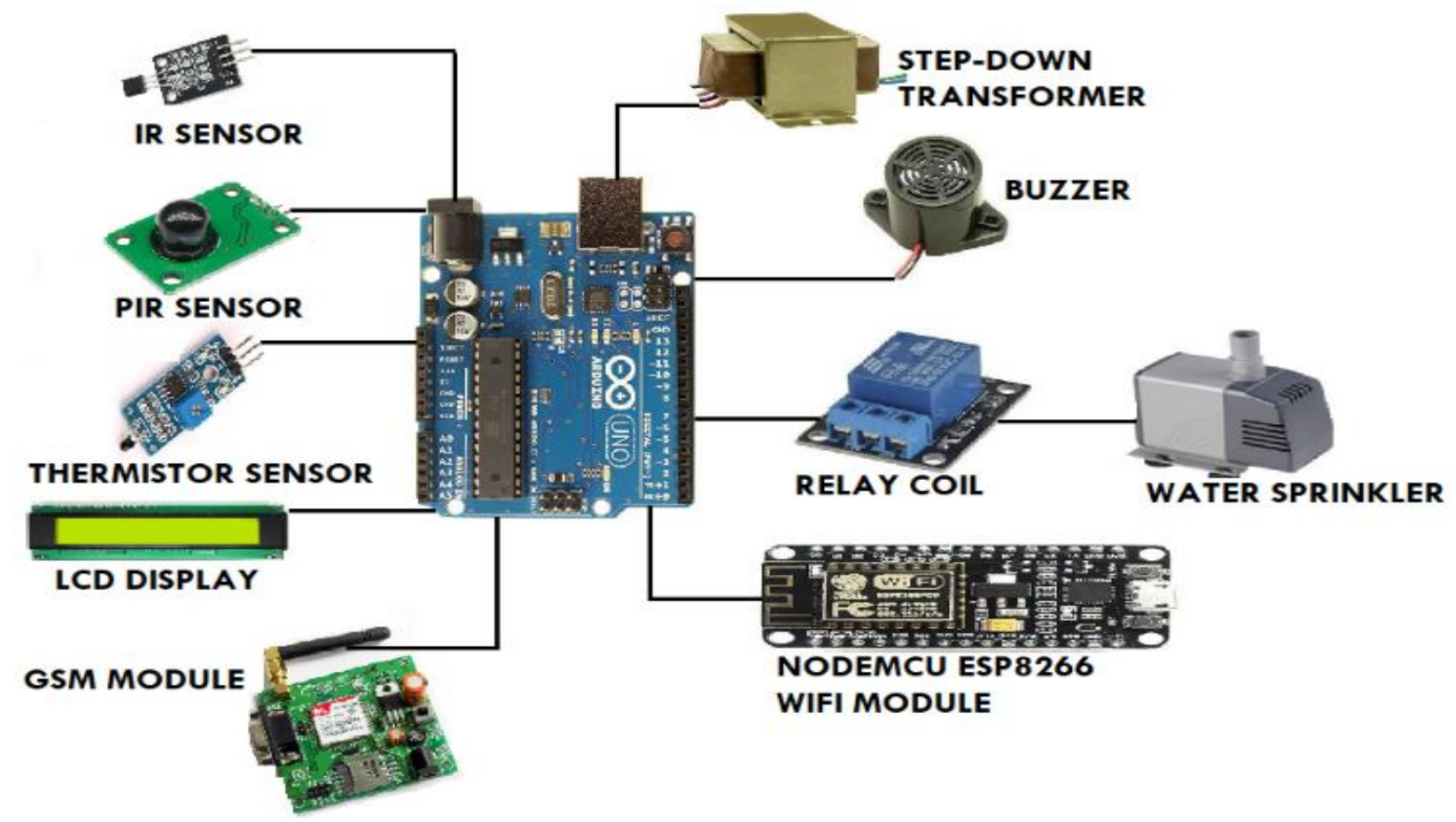

Fig 2: System Architecture of Assembly point 2-Fire Detection and Water Sprinkler System

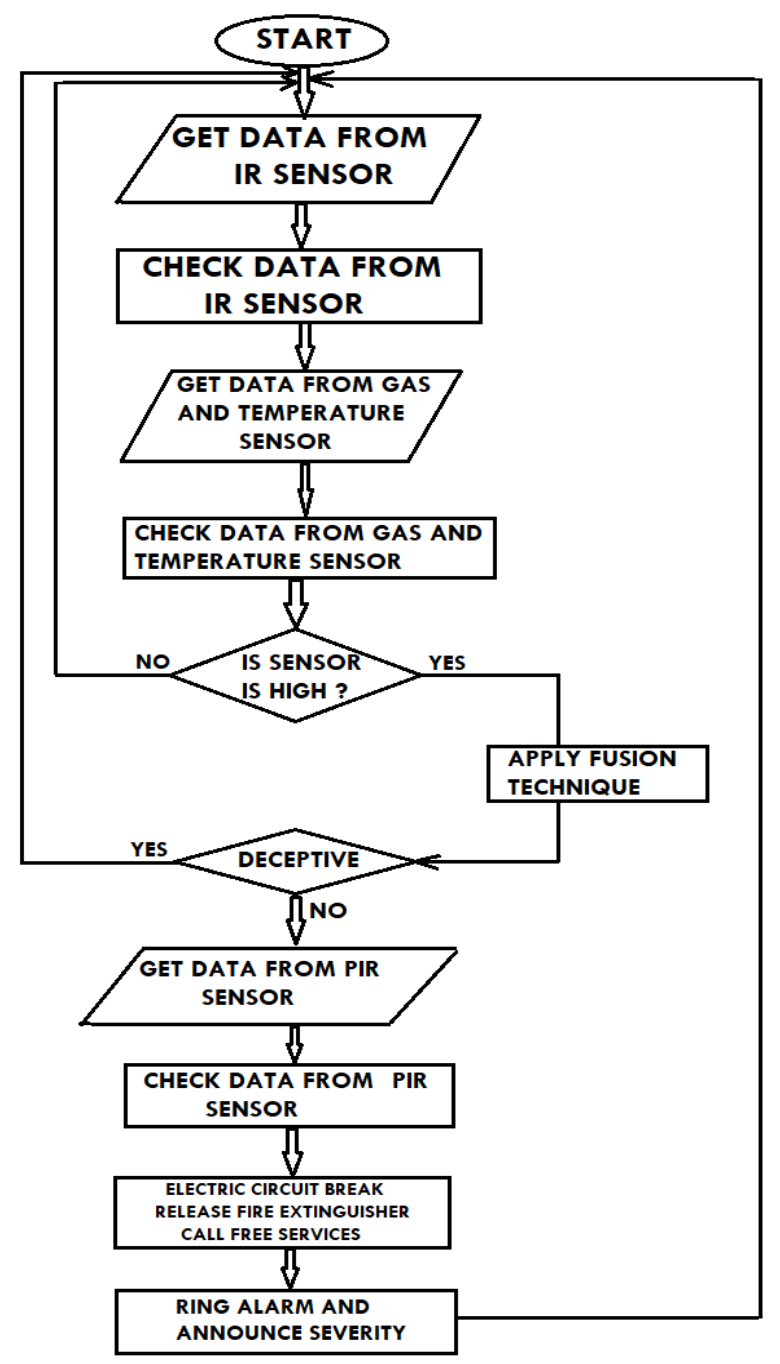

Fig 3: Flowchart of the System at Assembly Point 2

\section{ALGORITHM}

\subsection{Fuzzy Logic Algorithm}

A fuzzy logic based system works in three basic steps. It includes fuzzification, decision making (inference) and defuzzification and the inference system.

\subsubsection{Fuzzification}

Fuzzification is a process by which a crisp quantity is converted to fuzzy quantity. For this the input variables that correspond to real world parameters are expressed in terms of fuzzy membership functions.

\subsubsection{Decision Making (Inference)}

Decision making corresponds to the process of reaching conclusions based on input values provided. For this base rule is used. It could be said that rules control the total fuzzy system. Normally fuzzy rules is of the form "IF and THEN consequence". The premises are defined by the input membership functions.

\subsubsection{Defuzzification}

Defuzzification is the conversion of a fuzzy quantity to a precise quantity.

\subsubsection{Fire Detection System}

Multi sensor based fire detection systems are one of the important current development in automatic fire detection technology. The two main objectives of this progress are still unacceptable false alarm behavior and improvements in fire detection capabilities of the systems. This system basically takes inputs from three different sensors (smoke, light and temperature) and evaluation and processing of the sensor signals is carried out by using fuzzy logic. The output obtained from different sensors are applied to signal processing unit. The processed values are provided to the 
basic fuzzy inference system. The crisp value will undergo fuzzification. They are used to produce fuzzified output based on the rules and the defuzzified output will be produced as a result.

\subsubsection{Fuzzy Logic for Location Detection}

Fuzzy logic has been chosen to decide exact location of fire. Because fire could rise in any location within the monitored area. Since the number of sensors to detect the fire are mounted on different positions of the sensor deployment area, sometimes detecting the fire location precisely becomes difficult. Without the fuzzy logic from the actual readings of the adjacent sensors, relative position of the fire can be determined. Since, the exact angle from three or four different sensors mounted in different location, one single location point can be estimated. However, it does not provide satisfactory results in various scenarios especially whenever the range of the sensors are less and if there is large number of sensors. For larger area monitoring with inexpensive short range sensors this type of situation can easily happen. Hence, fuzzy logic algorithm has been incorporated in to this system. It determines the exact angle to target the fire position. Appropriate location is determined based on the fuzzy logic and considering intensity of adjacent sensors readings mounted in different positions.

Fuzzy set is a set of ordered pairs given by:

$$
A=\{(x, \mu A(x)): x \in X\}
$$

Where $\mathrm{X}$ the universe of discourse, $\mu \mathrm{A}(\mathrm{x})$ the grade of membership of $\mathrm{x}$ in $\mathrm{A}$ and, $\mu \mathrm{A}(\mathrm{x})$ lies in the interval $[0,1]$.

The shapes of popular membership functions are triangular, trapezoidal, Gaussian etc. The triangular and trapezoidal membership functions are illustrated in figures 4.1 and 4. 2 . The only restriction being that these functions take values between $[0,1]$. Experience helps in determining suitable functions for particular scenarios. A triangular membership function illustrated in figure 4.1 is fully specified by three parameters $(\mathrm{a}, \mathrm{b}, \mathrm{c})$ as follows:

$$
\text { triangle }(x: a, b, c)=\left\{\begin{array}{cl}
0, & x \leq a \\
\frac{x-a}{b-a}, & a \leq x \leq b \\
\frac{c-x}{c-b}, & b \leq x \leq c \\
0, & c \leq x
\end{array}\right.
$$

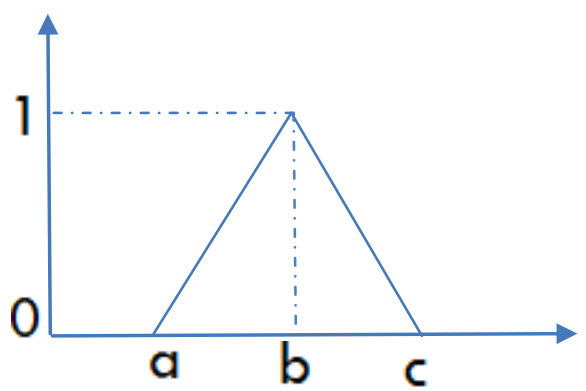

Fig 4: Triangular membership Function A trapezoidal membership function is specified by four parameters (a, b, c, d) as follows:

$$
\operatorname{triangle}(x: a, b, c, d)= \begin{cases}\frac{x-a}{b-a}, & x \leq a \\ 1, & b \leq x \leq c \\ \frac{d-x}{d-c}, & c \leq x \leq d \\ 0, & d \leq x\end{cases}
$$

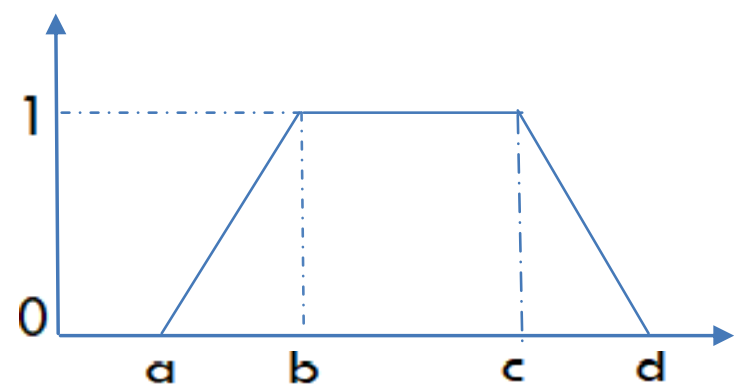

Fig 5: Trapezoidal membership function

\subsubsection{Fuzzy control rules}

Let $x 1, x 2, x 3$ be the Fuzzy Logic Controller (FLC) inputs and $\mathrm{y}$ the output.

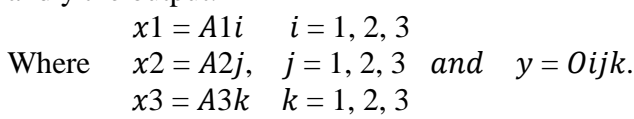

The fuzzy relationship $R=U(A 1 j k \times A 2 i k \times A 3 i j) \times O i j k$.

\subsubsection{Fuzzy output}

After defuzzification, the output is given by the expression

$$
Y=\frac{\sum_{i=1}^{3} \sum_{j=1}^{3} \sum_{k=1}^{3} d_{i j k} \mu_{A 1 i}\left(x_{i}\right) \mu_{A 2 j}\left(x_{j}\right) \mu_{A 3 k}\left(x_{k}\right)}{\sum_{i=1}^{3} \sum_{j=1}^{3} \sum_{k=1}^{3} \mu_{A 1 i}\left(x_{i}\right) \mu_{A 2 j}\left(x_{j}\right) \mu_{A 3 k}\left(x_{k}\right)}
$$

\section{CONCLUSION}

The Industrial based intelligent emergency response system can reduce the casualties of the disaster in industries to prevent the employees, industrial machines and infrastructure by providing appropriate evacuation guidance. The system can also aid disaster fighting with the help of water sprinklers because it allows for a quick assessment of the disaster with decentralized control that can intelligently guide evacuees based on the detection of humans.

\section{REFERENCES}

[1] Lakshmana Phaneendra Maguluri, Tumma Srinivasarao, Maganti Syamala, R. Ragupathy, N.J. Nalini, "Efficient Smart Emergency Response System for Fire Hazards using IoT", International Journal of Advanced Computer Science and Applications, Vol. 9, No. 1, 2018

[2] MD Iftekharul Mobin, MD Abid-Ar-Rafi, MD Neamul Islam and MD Rifat Hasan, "An intelligent fire detection and mitigation system safe from fire (sff)", International journal of computer applications (0975 - 8887), volume 133 - no.6, January 2016.

[3] MS. Vidhy Khule, MS. Divya Dhagate and MS. Rajashree Kadam, "Design and Implementation of a fire detection and control system for automobiles using fuzzy logic", ISSN: 2277-9655, April, 2017.

[4] Ionuţ-Lucian Homeag, Radu Pârlog-Cristian and Mircea Covrig, "Efficiency increase for electrical fire detection and alarm systems through implementation of fuzzy expert systems", ISSN: 1454-234x, 2013.

[5] Aiswarya Muralidharan and Fiji Joseph, "Fire Detection System Using Fuzzy Logic", ISSN: 2277-9655, April, 2014.

[6] Ms.Simmi Sharma, Diwankar Singh, Sanjay Singh Rathore and Paras Bansal, "Fire Detection System with 
GSM Using Arduino", Imperial Journal of Interdisciplinary Research (IJIR), ISSN: 2454-1362, 2017.

[7] $\mathrm{Li} \mathrm{Da} \mathrm{Xu}, \mathrm{Wu} \mathrm{He}$ and Shancang $\mathrm{Li}$, "Internet of Things in Industries: A Survey", IEEE Transactions on Industrial Informatics, November 2014.

[8] Chang-Su Ryu, "IoT-based Intelligent for Fire Emergency Response Systems", International Journal of Smart Home, 2015.

[9] ZHANG Ying-cong, YU Jing, "A Study on the Fire IOT Development Strategy", Procedia Engineering 52 (2013).

[10] Vikshant Khanna, Rupinder Kaur Cheema, "Fire Detection Mechanism using Fuzzy Logic", International Journal of Computer Applications (0975 - 8887), Volume 65- No.12, March 2013.

\section{AUTHORS PROFILE}

Vishal B. Rawat, BE, Computer Science and Engineering Student at Brahma Valley College of Engineering and Research Institute, Nashik under University of Pune.

Mangesh A. Singh, BE, Computer Science and Engineering at Brahma Valley College of Engineering and Research Institute, Nashik under University of Pune.

Swati A. Suryawanshi, BE, Computer Science and Engineering at Brahma Valley College of Engineering and Research Institute, Nashik under University of Pune.

Priti S. Chabukswar, BE, Computer Science and Engineering at Brahma Valley College of Engineering and Research Institute, Nashik under University of Pune.

Hemant D. Sonawane, ME, BE Computer Engineer was educated in Pune University. Presently he is working as a Head of Computer Department of Brahma Valley College of engineering and Research Institute, Nashik, Maharashtra, India. He has presented papers at National and International Conferences and also published paper in National and International Journals on various aspects of Computer Engineering and Networks. 